\title{
Beyond Informed Consent
}

\section{Educating the Patient}

\author{
Lawrence H. Brenner JD, Alison Tytell Brenner BA, \\ Daniel Horowitz MD
}

Published online: 5 December 2008

(C) The Association of Bone and Joint Surgeons 2008

\begin{abstract}
The informed consent doctrine was conceived as a basis for allowing patients to meaningfully participate in the decision-making process. It has evolved into a formal, legal document that reflects a desire by physicians and surgeons to have patients execute "waivers of liability." In the process it has lost its educational value by shifting the emphasis to obtaining a "preoperative release" from an exchange of information upon which a patient can make important decisions about their healthcare choices. This is unfortunate because, in the process, both patients and physicians have suffered. Patients have become alienated from the informed consent process and, paradoxically, physicians and surgeons may have created more liability exposure through this alienation. We propose that by returning to an educational model, the patients will develop a greater sense of control, become more compliant, and potentially experience improved healthcare outcomes.
\end{abstract}

Each of the authors certifies that he or she has no commercial associations (eg, consultancies, stock ownership, equity interest, patent/licensing arrangements, etc) that might pose a conflict of interest in connection with the submitted article.

\section{H. Brenner}

Department of Orthopedic Surgery, Yale University,

New Haven, CT, USA

L. H. Brenner $(\bowtie)$

Lawrence Brenner Law, 300 Market Street, Suite 130,

Chapel Hill, NC 27516, USA

e-mail: 1b@lawrencebrennerlaw.com

A. T. Brenner

University of North Carolina at Chapel Hill, Chapel Hill, USA

D. Horowitz

Department of Orthopedics, University of Utah, Salt Lake City, USA
There may also develop an alliance between the patient and the physician or surgeon, such that the seeds of an antagonistic or litigious relationship will not be planted before treatment begins. Liability reduction, therefore, may more likely arise from the educational model.

\section{Introduction}

For the most well-intentioned surgeon, the purpose of the informed consent doctrine is confusing and may leave them bewildered about the information that needs to be conveyed to patients. The doctrine remains simple in the abstract-a surgeon or physician needs to inform the patient of common or serious risks that are inherent in the procedure to be performed and material to the patient's decision. The doctrine of informed consent was stated succinctly by the court in Cobbs v. Grant [8], "the patient's interest in information does not extend to a lengthy polysyllabic disclosure on all possible complications. A minicourse in medical science is not required; the patient is concerned with the risk of death or bodily harm and the problems of recuperation." Since there is a heightened concern about professional liability exposure, surgeons have come to fear that if they omit a potential, rare, or obscure complication that materializes, they will be subject to a successful lawsuit by their patient. This fear is unwarranted since a patient must prove in an informed consent case a cause-and-effect relationship between the alleged inadequate disclosure and the patient's outcome. In order to do so, they must demonstrate by an objective standard that the surgery would have been refused had the risk been disclosed. The courts define such an objective standard as the choices that a reasonable, average patient 
under similar circumstances would make. It is implausible that a patient who has been advised of the major and serious risks of a procedure would have elected not to undergo the procedure if advised of secondary and less common risks. If the possibility of paralysis would not alter the patient's decision to undergo the surgery, then the patient cannot reasonably claim that knowledge of prolonged hospitalization, which is much milder than the potential of paralysis, would have caused him or her to decline surgery.

Nonetheless, the surgeon's fear of litigation has led to the development of informed consent forms that no longer serve as educational tools but rather as waivers of liability.

Although the courts have labeled the doctrine "informed consent," surgeons and patients would be better served if they thought of the legal requirement as a component of "patient education."

\section{Understanding Informed Consent}

Victor Ali [1] advances the proposition that informed consent forms are no longer tools to assist the patient in medical decision making, but rather they are similar to liability releases. Ali views the primary goal of the surgeon in the informed consent process to be to protect herself from legal liability by providing the patient “... with massive amount[s]" of medical information [1]. The educational conversation between doctor and patient has been lost, and has been replaced by a singular event in which papers are executed much like lease agreements.

The legalistic approach to informed consent has become disconnected from the process of communicating in a clinical setting, and the "waiver of liability" approach "perpetuates a view of informed consent as something detached from the unique rhythm of the clinical settingsomething imposed on medicine by an uncomprehending legal system" [3]. Informed consent documents are generally written or revised by the hospital attorneys. Consequently, they appear as legal documents, with little, if any, appreciation for the capacity of patients to understand the meaning of the form in the same way they rarely can understand other legal documents.

Grundner [12] studied these forms to determine if they were comprehensible, and therefore educational. He examined surgical consent forms in five hospitals in Southern California using two standard readability tests, the Fry Readability Scale and the Flesch Readability Formula. The Flesch formula, given as a reading grade level, assesses readability on the basis of the average number of syllables per word and words per sentence, and the Fry scale, given as number of years of education required to understand a document, uses the average number of syllables across three 100 word blocks and the average number of sentences across three 100 word blocks. What Grundner discovered was that the readability of all five was approximately equivalent to that of the material intended for upper-division undergraduate and graduate students. Four of the five forms were written at the level of a scientific journal, and the fifth at the level of a specialized academic magazine. On a readability scale of 0 to 10 , with 0 being the most difficult to read, four of the five forms scored under 1.5 and the fifth only slightly better. Grundner concluded that "if every surgical consent form in the country were subjected to similar analysis, few would pass" [12]. Sudore et al. [17] expands on Grundner's conclusions, showing that many patients with the capacity to consent required several readings to fully understand the informed consent form, and that low literacy, in particular, required a more in-depth conversation to ensure comprehension. The benefit of viewing the informed consent process as a component of a broader educational process can best be demonstrated by examining the impact of comprehensive patient education on patient outcomes.

Evidence suggests that proper informed consent has a direct impact on the quality of healthcare services $[5,6,10$, 15]. The psychologist Irving Janis has shown in his studies on the impact of preoperative disclosure of information on postoperative outcomes that the phenomenon of "anticipatory fear" is associated with the patient's ability to cope with postoperative stress. Andrews [2] discussed Janis's studies as follows: "Janis speculates that the patient needs to prepare for the threatening events of surgery and its effects through a process of rehearsing the impending events and experiences. According to Janis, the "work of worrying" helps the patient develop a psychological immunity to the stressful effects of surgery by allowing the patient to establish accurate expectations and psychological defenses for coping with threatening circumstances. In his later work, Janis understands the effect of disclosure in terms of an "emotional inoculation" that prevents the patient from being overwhelmed by the threatening events and sensations accompanying surgery" [2].

Andrews's systematic review confirmed this relationship between preoperative disclosure and postoperative outcomes. One study included in the review focused on abdominal operations and found that patients "who received information about the sensations to be expected as a result of the operation, as well as postoperative instruction in relaxation exercises, needed fewer narcotics for pain during recovery and were sent home an average of 2.7 days sooner than patients without these instructions" [2]. Another study by Greenfield et al. [11] concluded that the interpersonal aspect of the physician-patient interaction may have an appreciable influence on a patient's health outcomes. Greenfield and colleagues compared patients who were 
provided preoperative education with those who were not and found a distinctive improvement in outcome in the experimental group over the control [11]. The wellinformed patient has a greater sense of control and is also more likely to be a compliant patient $[1,18]$.

Explaining to patients what to expect during and after surgery has not been traditionally required by the informed consent doctrine, notwithstanding the fact they are an important, and often missing, component in creating realistic expectations and in assisting the patient in the recovery process $[4,13]$. Malpractice lawsuits are often predicated on disappointed patients when their expectations are not fulfilled. Applying the principles of Janis, Andrews, and Greenfield will assist in harmonizing patient's expectations with the likely results [2, 11]. Although these are not technical components of the informed consent process, aligning expectations with reality will create fewer disappointed patients, ie, those likely to question the surgeon's care and file a lawsuit.

The informed consent process works from the assumption that there is relative certainty concerning the advantages and disadvantages of treatment choices. Medicine, however, may not have reached the level of certainty that allows for easy and clear-cut decision making, and a key component of informed consent is, therefore, effectively communicating uncertainty $[7,9,14,16]$.

Gutheil et al. [13] theorized that patients look to their surgeon for reassurance in the face of uncertainty in much the way a child looks to a parent. Gutheil suggests surgeons often accept this infantile interpretation that they are the allknowing healer. This creates a paternalistic relationship so that a patient who is reassured and experiences an unsatisfactory outcome is likely to feel that something went wrong, and that their surgeon must have made a mistake. Gutheil has developed a model for communicating uncertainty to patients based upon the formation of a "therapeutic alliance." This alliance is grounded in the recognition that, "patients invoke wishful or magical thinking as a defense against feelings of helplessness" [13]. As a reaction to these feelings of helplessness, patients look to physicians for reassurances that "there is nothing to worry about." Take, as an example, the patient who tells the physician "I am scared." If the physician reassures the patients by stating, "don't be," the patient may process the reassurance as a promise or guarantee of a good outcome. Dr. Guthiel states, "...patients and families who have experienced tragic disappointments in their expectations of medicine attempt to assuage their grief, helplessness, and despair by suing - that is, blaming the physician. In doing so, they often fail to discriminate among errors of negligence, other errors, natural variations, and acts of fate" [13].

Guthiel cautions that " the physician should resist the logical move of dismantling the unrealistic foundation of the narcissistic alliance by confronting it head on; one cannot expect to take away the wishful thinking (and the resulting unhealthy attachment to the physician) without providing a different kind of comfort-and attempting a different kind of alliance" [13].

This alliance begins when the physician empathizes with the patient's wish for certainty. The "scared" patient could be told that the physician understands their fear and that the patient should not be ashamed of it. Explicit identification with the patient's desire for a certain outcome could be expressed through remarks such as "I wish I could perform surgery that only made patients as healthy and active as they want to be." As Guthiel states "...the patient can now approach the physician not as a childhood fantasy ideal, but as another vulnerable human being facing - and hence, sharing-the same uncertainty" [13]. Instead of squaring off defensively against each other, doctors and patients are brought together by the shared acknowledgement of clinical uncertainty and the fantasy used to deny it. Once the uncertainty is confronted and acknowledged, the physician must emphasize the continuing alliance through statements such as "I'll be with you every step of the way." After this alliance is formed, the physician and patient are free to share the emotions that result from the patient's outcome. If the patient's surgery has no complications and the patient recovers to a full and active life, the physician and patient can celebrate the outcome. Similarly, if surgery is unsuccessful (or disappointing), the physician and patient will be able to deal realistically with the outcome.

\section{Discussion}

Commentators have noted that the written informed consent forms more closely resemble releases of liability than they do educational tools. To the extent the forms have been studied, the literacy level is too high for the majority of patients. Other studies on patient education reveal a potential relationship between patient education and improved health care outcomes. Since malpractice claims are filed by patients who have suffered poor outcomes, the value of the informed consent process in reducing malpractice losses may be undermined by the tendency to approach informed consent as a means to "protect" the surgeon rather than to educate the patient. Future studies should work towards the creation a new paradigm for informed consent forms. This paradigm would embrace patient education and repudiate forms generated by attorneys to absolve surgeons of liability exposure. What would further need to be studied is whether this new paradigm would produce better outcomes for patients, a stronger alliance between the patient and the surgeon and a reduction in the filing of malpractice claims. It is strongly 
suggested that physicians and surgeons conduct an assessment of their own forms. They should engage their patients in this process of reassessment. They could generate a survey asking patients questions such as, (1) Do you believe the form has been created for your benefit? And (2) Do you feel informed about your choice of surgery?

Informed consent is a poorly studied phenomenon. The principal limitation in studying informed consent is that most of the literature focuses on the written component. To our knowledge, there are no large-scale studies that examine the discussion between physicians and patients regarding consent. Nor, to our knowledge, are there any large-scale studies on physician and surgeon attitudes toward the informed consent process. Do physicians and surgeons perceive the process as something imposed upon them by the judicial system or as a useful clinical tool to create an environment that will allow their patients to achieve the best possible outcomes?

Based upon our interpretation of the literature and experience, we make the following recommendations: (1) The informed consent form is not a substitute for educating a patient. It is merely evidence that appropriate discussion occurred. In addition to assuring that the patient has signed the informed consent document, these discussions must occur. (2) The forms should be designed to be understandable, and all care should be taken to ensure that comprehension is achieved, and the process should be viewed as a tool to educate rather than waive liability. (3) The surgeon should avoid the paternalistic approach in dealing with uncertainty and, instead, use uncertainty as the foundation for forming a therapeutic alliance. (4) A welleducated patient does not need to be presented with an exhaustive list of every conceivable complication. Rather, an educated patient needs to be an active participant in a dialogue about the inherent risks of the surgery that are important to the individual decision-making process, ie, the risks that are specifically of concern to that patient. For example, the complications of hand surgery may be more material to a concert pianist than the average patient. (5) An understandable note in the medical record that a discussion has occurred with the patient and/or the family may be far more effective as evidence of the discussion than a lengthy signed but incomprehensible form.

\section{References}

1. Ali V. Consent forms as part of the informed consent process: Moving away from "medical Miranda." Hastings Law J. 2003; 54:1575-1591.

2. Andrews LB. Informed consent statutes and the decisionmaking process. J Leg Med. 1984;5:163-217.

3. Appelbaum PS, Lidz CW, Meisel A. Informed Consent: Legal Theory and Clinical Practice. New York, NY: Oxford University Press; 1987.

4. Braddock CH 3rd, Edwards KA, Hasenberg NM, Laidley TL, Levinson W. Informed decision making in outpatient practice: time to get back to basics. JAMA. 1999;282:2313-2320.

5. Brody DS, Miller SM, Lerman CE, Smith DG, Caputo GC. Patient perception of involvement in medical care: relationship to illness attitudes and outcomes. J Gen Intern Med. 1989;4:506-511.

6. Brody DS, Miller SM, Lerman CE, Smith DG, Lazaro CG, Blum MJ. The relationship between patients' satisfaction with their physicians and perceptions about interventions they desired and received. Med Care. 1989;27:1027-1035.

7. Brownlee S. Overtreated. New York, NY: Bloomsbury; 2007.

8. Cobbs v. Grant 8 Cal. 2nd 229 (1972).

9. Fielding S. The Practice of Uncertainty: Voices of Patients in Medical Malpractice Claims. Westport, CT: Auburn House; 1999.

10. Frosch DL, Kaplan RM. Shared decision making in clinical medicine: Past research and future directions. Am J Prev Med. 1999;17:285-294.

11. Greenfield S, Kaplan S, Ware JE Jr. Expanding patient involvement in care. Effects on patient outcomes. Ann Intern Med. 1985;102:520-528.

12. Grundner TM. On the readability of surgical consent forms. $N$ Engl J Med. 1980;302:900-902.

13. Gutheil TG, Bursztajn H, Brodsky A. Malpractice prevention through the sharing of uncertainty. Informed consent and the therapeutic alliance. $N$ Engl J Med. 1984;311:49-51.

14. Hadler NM. The Last Well Person: How to Stay Well Despite the Health-care System. Montreal, Quebec, Canada: McGill-Queen's University Press; 2004.

15. Lerman CE, Brody DS, Caputo GC, Smith DG, Lazaro CG, Wolfson HG. Patients' perceived involvement in care scale: Relationship to attitudes about illness and medical care. J Gen Intern Med. 1990;5:29-33.

16. Payer L. Medicine and Culture. 2nd ed. New York, NY: Henry Holt \& Co; 1996.

17. Sudore RL, Landefeld CS, Williams BA, Barnes DE, Lindquist $\mathrm{K}$, Schillinger D. Use of a modified informed consent process among vulnerable patients: A descriptive study. J Gen Intern Med. 2006;21:867-873.

18. Weithorn LA, Scherer DG. Children's involvement in research participation decisions: psychological considerations. In: Grodin MA, Glantz LH, eds. Children as Research Subjects. New York, NY: Oxford University Press; 1994:133-180. 